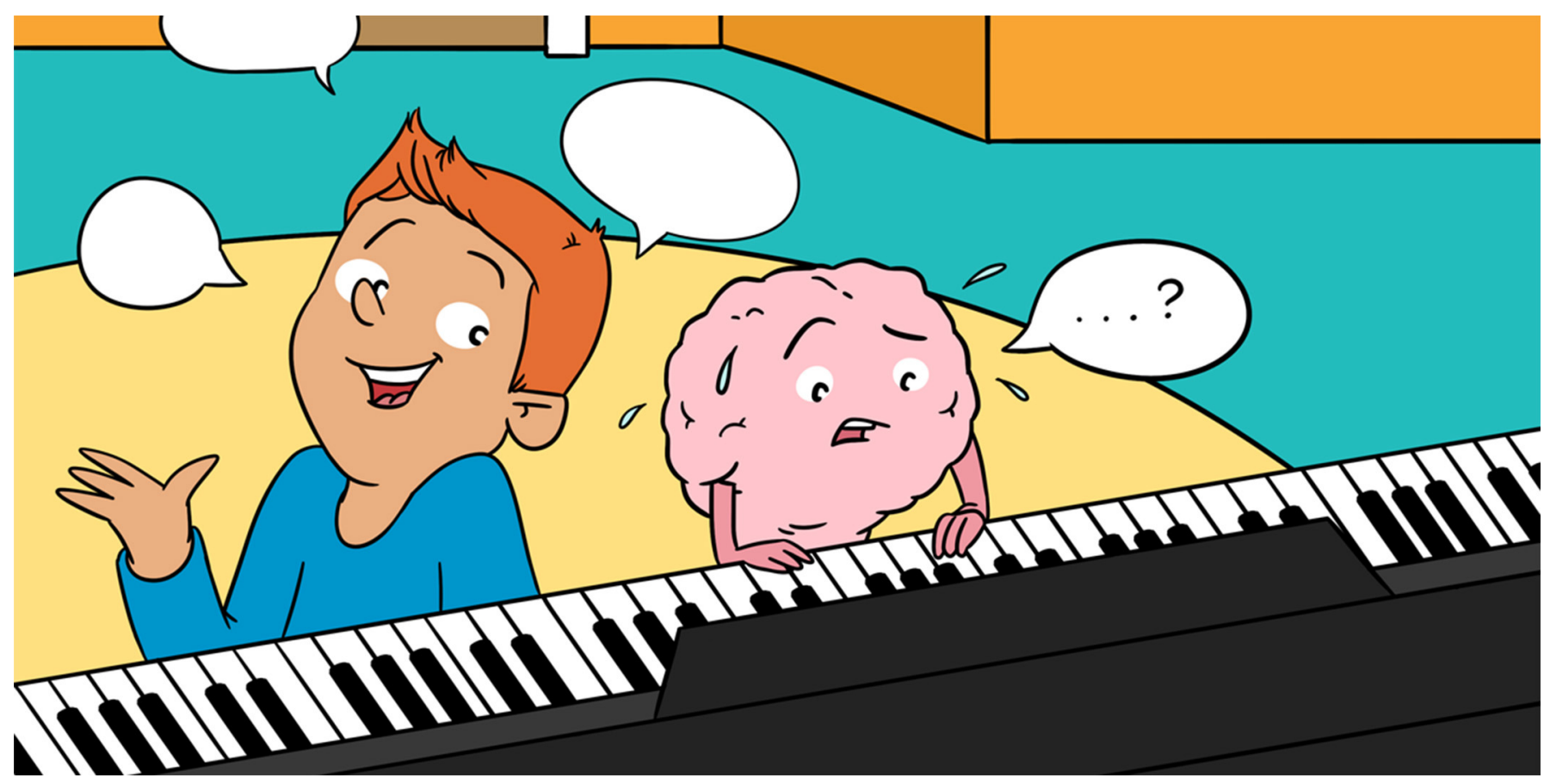

\title{
BRAIN STIMULATION CAN HELP US UNDERSTAND MUSIC AND LANGUAGE
}

\section{Maansi Desai ${ }^{1,2}$, Rachel Sorrells ${ }^{3}$, Matthew K. Leonard ${ }^{2}$, Edward F. Chang ${ }^{2}$ and Liberty S. Hamilton ${ }^{1,2,4^{*}}$}

${ }^{1}$ Department of Communication Sciences and Disorders, Moody College of Communication, University of Texas at Austin, Austin, TX, United States

${ }^{2}$ Department of Neurological Surgery, University of California, San Francisco, San Francisco, CA, United States

${ }^{3}$ Department of Neuroscience, College of Natural Sciences, University of Texas at Austin, Austin, TX, United States

${ }^{4}$ Department of Neurology, Dell Medical School, University of Texas at Austin, Austin, TX, United States

\section{YOUNG REVIEWERS:}

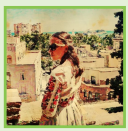

JULIA

AGE: 13

SYB

AGE: 14

\section{NEURON}

The cells that make up our brains and allow our bodies to perform various tasks.
Language and music are important ways that we communicate with each other. Talking out loud and playing a guitar may seem pretty different, but did you know that they use many of the same brain areas? Did you know that researchers have been able to study the language and music functions of the brain during brain surgery? In this article, you will learn about a procedure called electrocortical stimulation mapping (ESM), which is a procedure used during brain surgery to figure out which parts of the brain are important for speaking and playing an instrument.

\section{WHAT IS ELECTROCORTICAL STIMULATION?}

Our brains have millions of cells, called neurons that talk to one another by sending electrical signals. Because neurons can talk to each other, we can do many things, such as run, eat, speak, or even play a 
Figure 1

Our brains are made up of different regions that are important for helping us do different tasks. The highlighted areas were stimulated using ESM. The purple areas are in an area of the brain called the frontal lobe and are important for speech and music. The blue areas are in the parietal lobe and these areas have a role in both speech and music. The green areas are part of the temporal lobe and are important for speech. The gray, wand-like device is an ESM stimulator, which sends electricity (yellow lightning bolt) into one of the colored parts of the brain to test its function.

\section{EPILEPSY}

A brain disorder where brain cells (neurons) are too active, causing a person to

have seizures.

\section{TUMOR}

An abnormal mass in the brain that can cause a variety of symptoms, including seizures.

\section{GYRI/GYRUS}

The bumps on the surface of the brain.

ELECTROCORTICAL STIMULATION MAPPING (ESM)

A procedure in which different brain areas are stimulated with electricity, to interrupt different functions in the brain, like speaking or moving. ESM allows doctors to determine which brain areas are important for various functions.

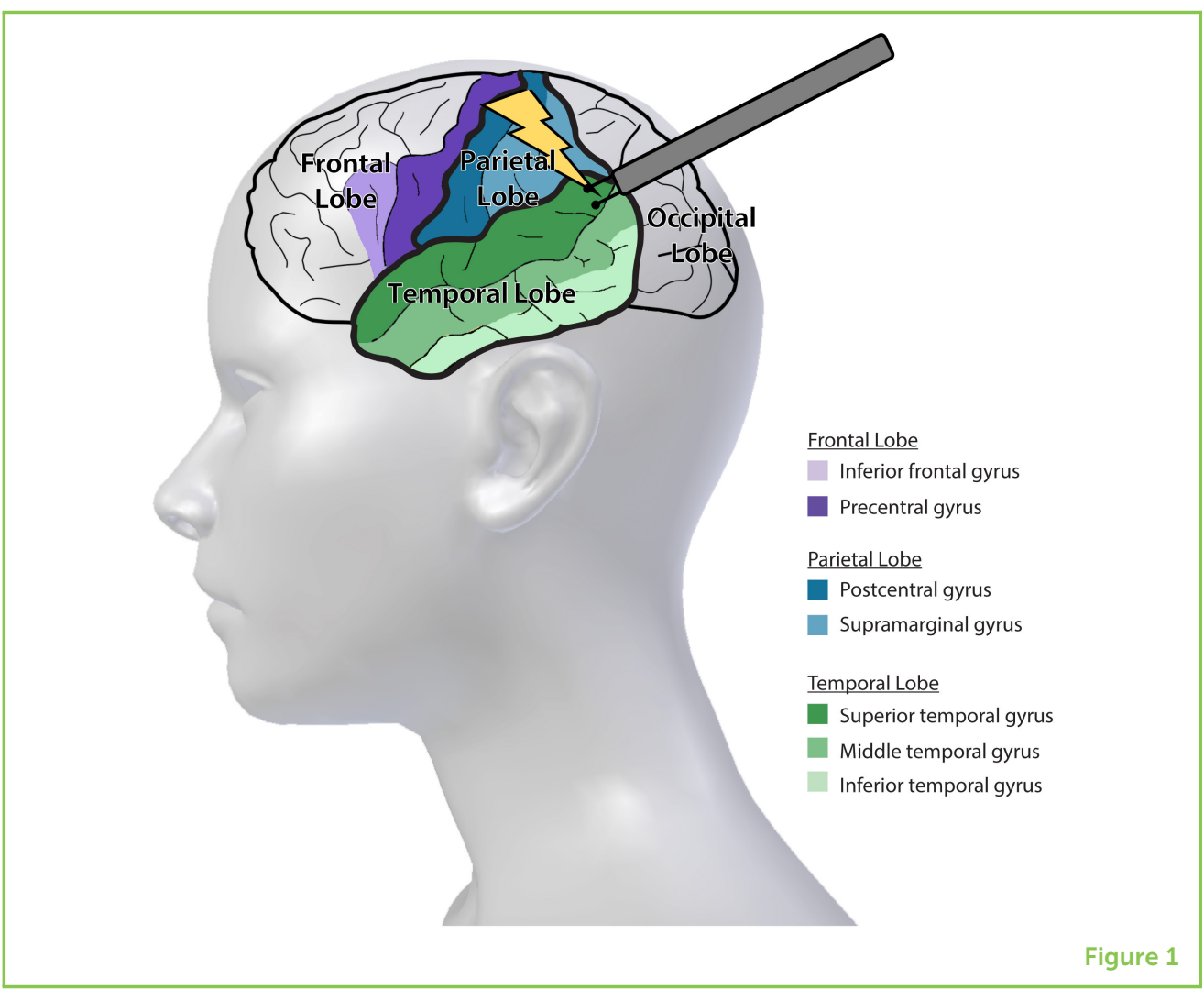

musical instrument! But what happens when these neurons are not working correctly? In people with epilepsy, the neurons may be too active, causing seizures. Or, in people with brain tumors, some cells may grow abnormally, and sometimes this can cause seizures too. Some patients with brain tumors or epilepsy have symptoms that may not be completely cured with medication, so they may need surgery to remove the tumor or the parts of the brain that cause seizures. If a patient's tumor or epilepsy is in the language part of the brain, it is important to make sure that the patient will be able to talk and understand speech after surgery. For this reason, surgeons want to be sure not to remove those important areas of the brain.

The brain is divided up into four main lobes, or regions, called the frontal, parietal, temporal, and occipital lobes. Smaller brain areas in the parietal, frontal, and temporal lobes, called the superior temporal gyrus, precentral gyrus, post-central gyrus, and inferior frontal gyrus (Figure 1), have been shown to be important for language [1]. Each of these brain areas has a role in listening and understanding, speaking, moving, and feeling. To avoid damaging these brain areas during surgery, surgeons use a technique called electrocortical stimulation mapping (ESM), which is a brain-mapping tool. ESM can help surgeons figure out which brain areas are important for speech. To do so, the surgeon uses a wand-like device called a stimulator, with two small electrodes, to send tiny amounts of electricity to different parts of the brain. This electricity temporarily changes the way neurons 
communicate with one another. By stimulating the brain, it is possible to cause the patient to make mistakes while they speak or to cause the patient to stop speaking altogether.

For patients who are musicians, it is also important that brain surgery does not harm their ability to continue playing music. As with speech, the surgeon can use ESM to stimulate different parts of the brain to see if the stimulation makes the patient stop being able to play an instrument. It is quite amazing to see a person playing guitar during brain surgery! By identifying the brain areas important for playing music, the surgeon can be careful not to damage these areas during surgery. In Figure 1, all the colored parts of the brain have been shown to activate while people speak, and some of the regions in the temporal, parietal, and frontal lobes also seem to be involved in playing music.

For most individuals, speech and music are important for communication, whether it is to verbally hold a conversation or to non-verbally express themselves in an artistic manner. Understanding the specific areas of the brain for these two forms of communication is not only important during brain surgery-it can also help scientists build better tools to improve communication, especially in people who have suffered a stroke or are paralyzed and have lost their ability to speak or move.

\section{WHAT DO PATIENTS DO DURING ESM?}

ESM is a unique procedure because it must be performed while the patient is awake during brain surgery. How does this normally happen? First, the patient is given medication so that he or she does not feel any pain. Next, the surgeon will ask the patient to perform a variety of tasks involving speaking, listening, and moving. For example, in a speech repetition task, the patient hears something like, "say kitty cat," and the patient responds by repeating the words "kitty cat." While the patient is performing this task, the surgeon will use an ESM stimulator [2] on different areas of the brain. When the stimulator touches a critical speech area of the brain, it can interfere with the patient's ability to speak.

A speech error that is made during ESM, where a patient switches phonemes when trying to say a given word (like saying "tat" instead of "cat").

PHONEMES

The individual sounds made when trying to pronounce letters to create words.
Amazingly, there are many kinds of mistakes that ESM can cause the patient to make. One type of mistake is called arrest, because the patient cannot say anything at all. Another mistake is when a patient says "kitty tat" instead of "kitty cat." This is called substitution and is a type of error called a phonological error, because the patient is swapping the " $c$ " sound (or phoneme) for a " $t$ " at the beginning of "cat." When a patient makes a mistake while trying to speak during ESM, the doctors record which brain area causes which types of errors, to make sure the brain areas critical for communicating are not removed during the surgery. 
Figure 2

Some of the mistakes people make when speaking or playing an instrument during ESM These types of errors allow us to see which parts of the brain are responsible for language and music functions. Here, we have an example of some saying "kitty cat" and playing a sequence of notes on a piano keyboard. The squiggly lines with the words "kitty cat" above are pictures of the sound waves. The blue color shows that parts of the word or musical phrase were spoken or played correctly. Where the sound wave or piano keys are red, this shows that an error was made.

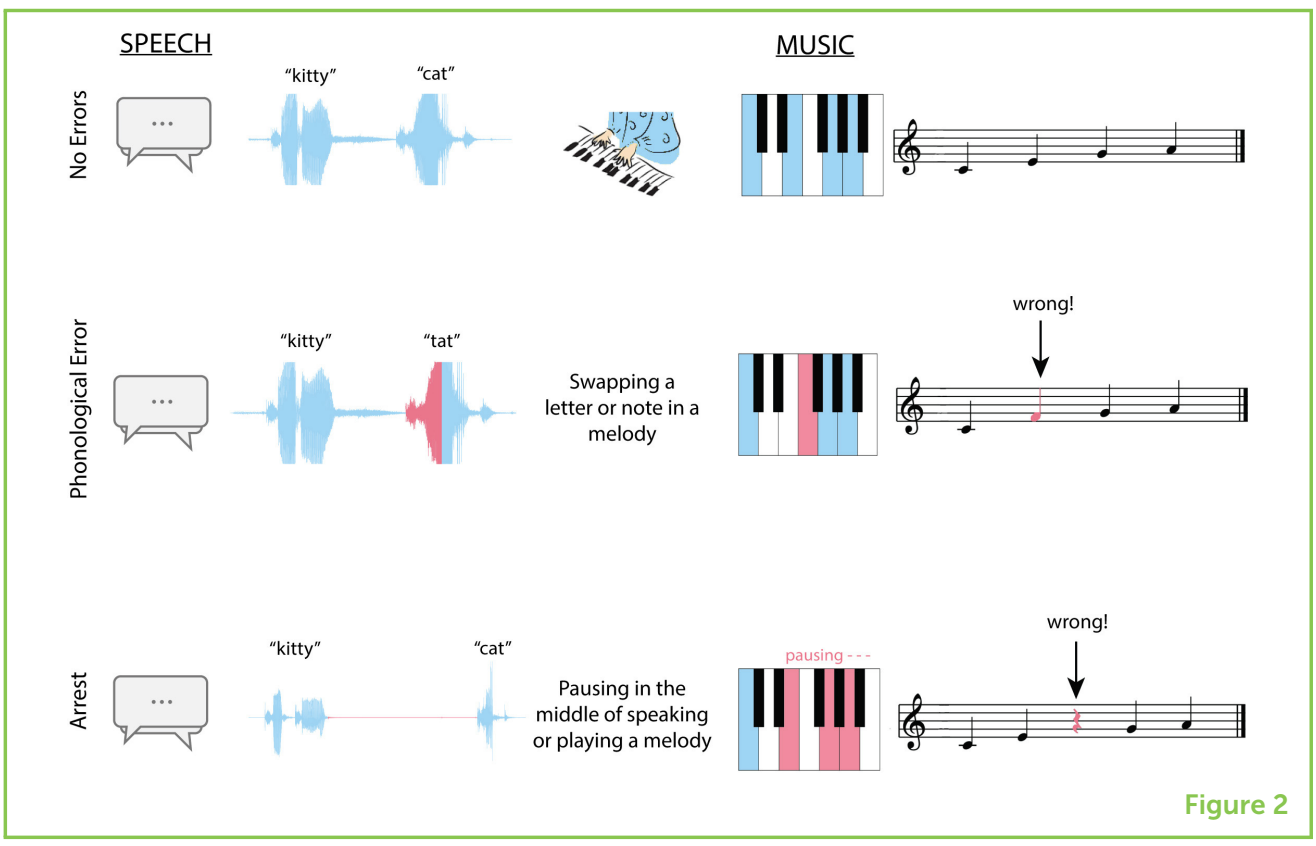

So, what about music?

\section{DO THE SAME BRAIN AREAS CONTROL TALKING AND PLAYING AN INSTRUMENT?}

Two patients (also musicians) who needed brain surgery wanted to make sure that the parts of their brains that allowed them to play music would not be affected by their surgeries [3].

The patients were tested for language and music. Using ESM, we were able to investigate whether the same brain areas play a role in both speaking and playing music, or whether there were separate brain areas for each. To test language, both patients were asked to count slowly from 1 to 30, or until told to stop. They were also asked to repeat words. While they were speaking, the surgeon used ESM to stimulate small areas within the colored regions of the brain (Figure 1) to see if the patients would make any mistakes. Each of these stimulation sites was tested between 1 and 18 times. For the music portion, the first patient was asked to play musical scales and a piano piece that he knew. The second patient strummed chords on a guitar. While the patients were performing these music tasks, the surgeons stimulated the same brain areas as tested in the language task. For both language and music, researchers looked at which types of mistakes (Figure 2) the patients made during stimulation, and which brain areas were involved in each.

The results from this study showed us that stimulating the inferior frontal gyrus (the purple area in Figure 1) caused the patients to stop (arrest), for both speaking and playing music! Scientists previously believed that this part of the brain was responsible for planning the 
Figure 3

Some regions of the brain mostly process speech and some regions mostly process music. There are also regions that do both. You can see that most of the middle and back regions of the inferior frontal and precentral gyri, in purple, are responsible for listening and speaking. The small portion in blue, which is mostly in the bottom part of the post-central gyrus, was shown to be involved in only playing music. The red region of the superior temporal gyrus seems to be involved only with speaking, not playing music. Image credit: https://pixabay.com/ illustrations/womens-music-instrumentpiano-1648811/

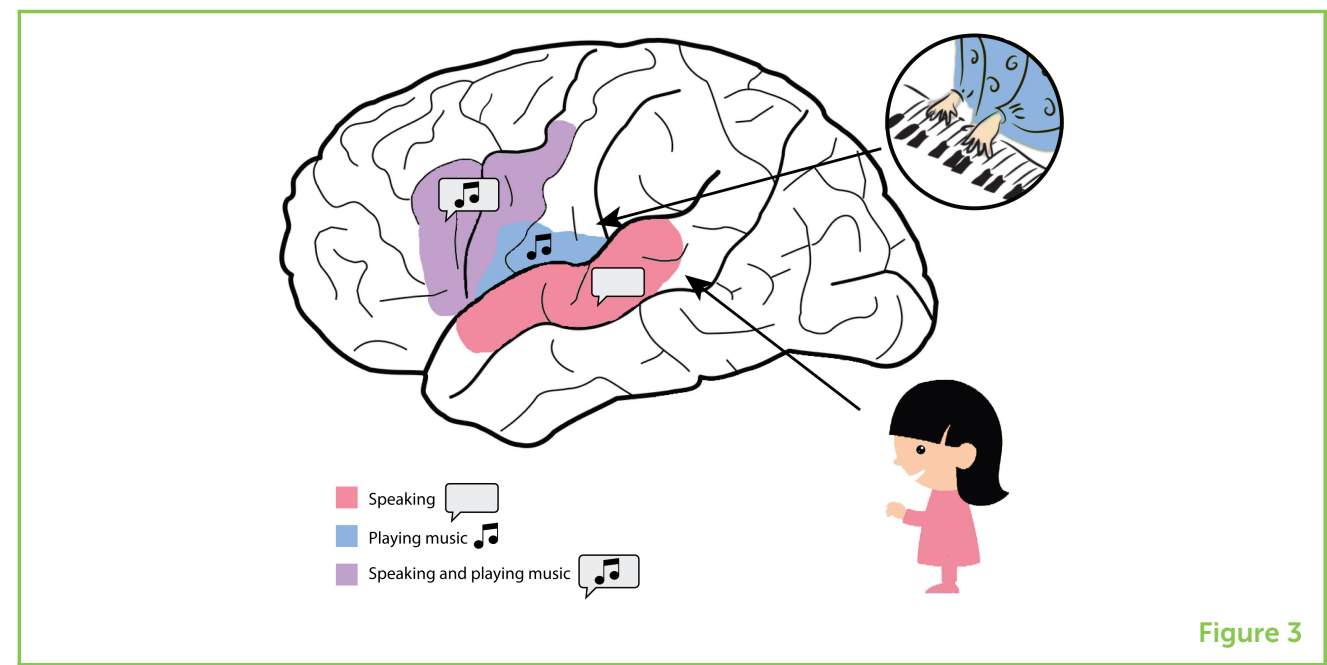

movements of the jaw, lips, and tongue so that we can talk. But we found out that this region of the brain controls hand movement, too. While there were some parts of the brain that caused mistakes for speaking only (in superior temporal gyrus, the pink area in Figure 3) or for playing music only (blue area in Figure 3), there were some parts of the brain that caused mistakes for both. These results seem to indicate that the inferior frontal gyrus has multiple functions in terms of how we communicate, and is not only used for speech. Since only two patients were studied, it is important to perform further ESM studies in other patients who are also musicians, so we can see if the results are similar in a larger group of people.

\section{WHAT HAVE WE LEARNED ABOUT THE BRAIN FROM SPEECH AND MUSIC?}

Music and language help us communicate. For decades, scientists have noticed how music and language are similar in the brain, but they have also found some differences [4]. In this article, we have discussed how ESM changes brain activity in brain areas important for music only, speech only, and brain areas that play a role in both. Through this study, ESM helped us learn that these brain regions are a little more complicated than we previously thought. Some brain areas, like the inferior frontal gyrus for example, seem to have multiple functions, such as helping with the abilities to both speak and play an instrument. In general, there is some disagreement over where the "music area" of the brain is located, compared with the "speech and language area," but these sorts of questions make neuroscience interesting. The ultimate goal of this and future research is to help scientists and non-scientists understand subjects like language and music thoroughly, so that humans can communicate better with one another! 


\section{AUTHOR CONTRIBUTIONS}

MD, RS, and LH contributed to the conception and literature review for this manuscript. MD, ML, and EC authored the original paper referenced in this work. MD and $\mathrm{LH}$ designed and created all the figures. All authors contributed to manuscript revision, read, and approved the submitted version.

\section{ACKNOWLEDGMENTS}

The authors would like to thank the patients at the UCSF Epilepsy Center who participated in the research tasks that made this work possible.

\section{ORIGINAL SOURCE ARTICLE}

Leonard, M. K., Desai, M., Hungate, D., Cai, R., Singhal, N. S., Knowlton, R. C., et al. 2018. Direct cortical stimulation of inferior frontal cortex disrupts both speech and music production in highly trained musicians. Cogn. Neuropsychol. 36:158-66. doi: 10.1080/02643294. 2018.1472559

\section{REFERENCES}

1. Leonard, M. K., Cai, R., Babiak, M. C., Ren, A., and Chang, E. F. 2016. The peri-Sylvian cortical network underlying single word repetition revealed by electrocortical stimulation and direct neural recordings. Brain Lang. 193:58-72. doi: 10.1016/j.bandl.2016.06.001

2. Ojemann, G., Ojemann, J., Lettich, E., and Berger, M. 1989. Cortical language localization in left, dominant hemisphere: an electrical stimulation mapping investigation in 117 patients. J. Neurosurg. 71:316-26. doi: 10.3171/jns.1989.71.3.0316

3. Leonard, M. K., Desai, M., Hungate, D., Cai, R., Singhal, N. S., Knowlton, R. C., et al. 2018. Direct cortical stimulation of inferior frontal cortex disrupts both speech and music production in highly trained musicians. Cogn. Neuropsychol. 36:158-66. doi: 10.1080/02643294.2018.1472559

4. Zatorre, R. 2005. Music, the food of neuroscience? Nature 434:312-5. doi: $10.1038 / 434312 a$

SUBMITTED: 03 July 2019; ACCEPTED: 31 January 2020; PUBLISHED ONLINE: 25 February 2020

EDITED BY: Sabine Kastner, Princeton University, United States

CITATION: Desai M, Sorrells R, Leonard MK, Chang EF and Hamilton LS (2020) Brain Stimulation Can Help Us Understand Music and Language. Front. Young Minds 8:16. doi: 10.3389/frym.2020.00016 

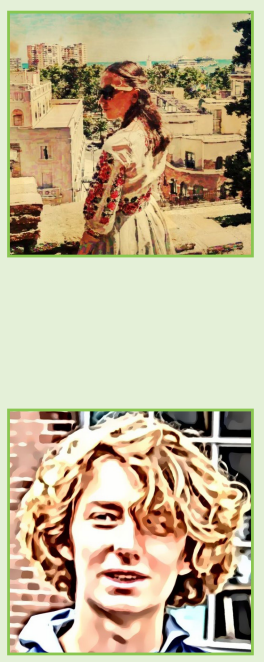

CONFLICT OF INTEREST: The authors declare that the research was conducted in the absence of any commercial or financial relationships that could be construed as a potential conflict of interest.

COPYRIGHT (c) 2020 Desai, Sorrells, Leonard, Chang and Hamilton. This is an open-access article distributed under the terms of the Creative Commons Attribution License (CC BY). The use, distribution or reproduction in other forums is permitted, provided the original author(s) and the copyright owner(s) are credited and that the original publication in this journal is cited, in accordance with accepted academic practice. No use, distribution or reproduction is permitted which does not comply with these terms.

\section{YOUNG REVIEWERS}

\section{JULIA, AGE: 13}

My name is Julia and I am a ninth grader from Berlin. I am a student who is very interested in math, chemistry, and sciences, especially neuro- and space sciences or quantum mechanics, but I enjoy learning languages too. At home I am talking with my parents in Ukrainian because originally we come from Ukraine and in addition I am studying German, English, and French at school. In my free time I really like playing the piano, dancing, and reading books.

\section{SYB, AGE: 14}

I am a ninth grader who is off playing (or watching) soccer whenever school work permits. I like math and science, and playing board games. I have my own 3D printed brain displayed in my room!

\section{AUTHORS}
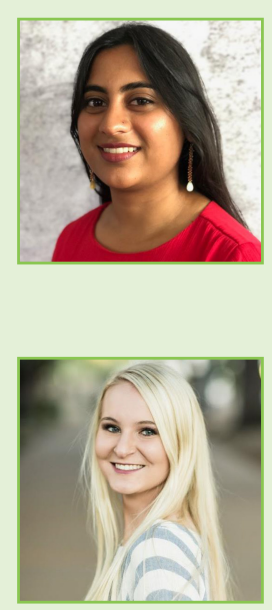

\section{MAANSI DESAI}

I am a Ph.D. student at the University of Texas at Austin, where I study how the brain represents all different types of sound, such as speech, music, and background noise. Following graduate school, I hope to apply my research in improving hearing assistive devices. In my spare time, I enjoy rocking climbing or bouldering, playing the piano, reading books, and planning my next travel adventure.

\section{RACHEL SORRELLS}

I am a recent graduate from the University of Texas at Austin where I studied Neuroscience. After graduation, I am now seeking a full-time job as I prepare to apply for graduate school. I hope to apply what I learned of Neuroscience to my love of music in my future job and in life. Along with science, I love to spend time playing piano and roller skating.

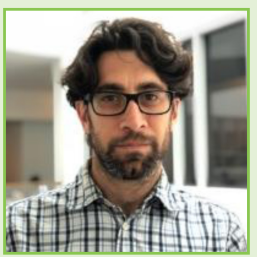

\section{MATTHEW K. LEONARD}

I am a cognitive neuroscientist at UCSF, where I study how the human brain understands spoken language. My research involves working with patients undergoing brain surgery, who volunteer to help us study speech using electrodes placed directly on their brains while they are being treated for neurological diseases. 


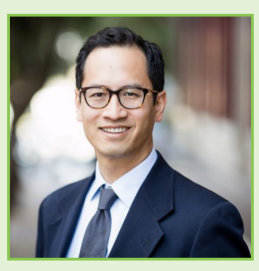

Outside of the lab, I try to spend as much time as possible playing piano, reading fiction, and hiking in the great outdoors around San Francisco.

\section{EDWARD F. CHANG}

I am a neurosurgeon at UCSF, where I treat patients with difficult-to-control epilepsy, brain tumors, movement disorders, and other neurological disorders. My research lab focuses on studying speech, movement, and learning through various brain mapping techniques in patients who are undergoing brain surgery. I am also the co-director of the Center for Neural Engineering and Prostheses at UCSF and the University of California, Berkeley. Outside of lab or being in the operating room, I enjoy spending time with my family, or sailing in the San Francisco Bay.

\section{LIBERTY S. HAMILTON}

I am a neuroscientist and an Assistant Professor in the Department of Communication Sciences and Disorders and the Department of Neurology at The University of Texas at Austin. My lab studies how the brain processes speech and other sounds in our environment using both EEG and intracranial recordings in patients with epilepsy. I also teach classes on language and the brain, neuroanatomy, and physiology. In my time outside of the lab, I love being in nature, whether that is on a hike, skiing, or in a kayak. I also enjoy playing the piano and cooking. *liberty.hamilton@austin.texas.edu 